\title{
Plasma histamine in patients with chronic renal failure and nephrotic syndrome
}

\author{
D S Gill, V A Fonseca, M A Barradas, R Balliod, J F Moorhead, P Dandona
}

\begin{abstract}
Plasma histamine concentrations were measured using a commercially available monoclonal antibody radioimmunoassay in 38 patients with nephrotic syndrome, end stage renal failure, those receiving haemodialysis, and those receiving continuous ambulatory peritoneal dialysis to determine whether histamine may mediate damage to glomerular capillaries and arterial endothelium. Plasma histamine concentrations were significantly increased in all four patient groups when compared with those of controls and were the highest in two patients with pruritus.

Raised plasma histamine concentrations in such patients are consistent with the hypothesis that histamine may contribute to the damage to glomerular capillaries and to arterial endothelium. These effects may be relevant to the pathogenesis of glomerular disease and atherosclerosis. Histamine may also contribute to the pathogenesis of pruritus in patients with chronic renal failure.
\end{abstract}

Histamine has an important role in the regulation of normal function and the changes which occur as a result of trauma and inflammation. It is one of the principal constituents of tissue mast cells ${ }^{1}$ and blood basophils ${ }^{2}$, and it is also found in gastric mucosa, ${ }^{3}$ vascular endothelial, ${ }^{4}$ and smooth muscle cells. ${ }^{5}$

The kidney synthesises and stores histamine, ${ }^{6}$ but very little is known about the role of histamine in renal pathophysiology. Prior treatment of rats with experimental induced glomerular nephritis with $\mathrm{H} 1$ receptor antagonists reduced the degree of proteinuria and onset of the disease. ${ }^{7}$ Other investigators have found that histamine antagonists or histamine depletors do not lessen renal injury in various experimental models of glomerular nephritis. ${ }^{8}$ Studies by Hollis and colleagues have shown that renal histamine content is increased in experimental diabetes mellitus and that this can be corrected by treatment with insulin or by the administration of a specific inhibitor of histamine synthesis. ${ }^{9}$ In man impaired clearance of injected labelled histamine has been reported in uraemia. ${ }^{10}$ Plasma histamine concentrations in renal disease, however, have not been measured due to the lack of adequately specific and sensitive methodology. A possible role for histamine in mediating the pruritus commonly seen in chronic renal failure has been proposed because parathyroid hormone in large doses induces the release of histamine from mast cells $^{11}$ and because parathyroid hormone is known to be very high in chronic renal failure. A recent study has reported increased plasma histamine concentrations in patients with pruritus in chronic renal failure. ${ }^{12}$

\section{Methods}

We studied 38 patients with renal disease in the following four clinical groups:

Group 1 Nine patients with nephrotic syndrome (six men, three women; median age 27 years, range 18-60 years). The median duration of nephrotic syndrome was six years (range one to 32 years). The median 24 hour urinary albumin excretion was $10.3 \mathrm{~g}$ (range 5.7-14.2 g), median plasma albumin $38 \mathrm{~g}$ (range $32-47 \mathrm{~g}$ ), median plasma creatinine $101 \mu \mathrm{mol} / 1$ (range 68-208 $\mu \mathrm{mol} / \mathrm{l}$ ), median plasma cholesterol $7.3 \mathrm{mmol} / \mathrm{l}$ (range 5.2 $15.7 \mathrm{mmol} / \mathrm{l})$. The diagnosis in these patients was minimal change glomerular nephritis in three, membranous glomerular nephritis in one, focal sclerosing glomerulonephritis in three, systemic lupus erythematosus in one, and amyloidosis in one. None of the patients was taking corticosteroids, two were hypertensive, and both of these were being treated with beta blockers.

Group 2 Nine patients with end stage renal failure five men, four women; median age 54 (range 23-62 years) with plasma creatinine concentrations of more than $400 \mu \mathrm{mol} / 1$, median creatinine clearance $690 \mu \mathrm{mol} / 1$ (500$1213 \mu \mathrm{mol} / 1)$. None of these patients had had dialysis. All nine patients were hypertensive and were being treated with nifedipine and diuretics; four patients were also taking metoprolol and one captopril. All patients were taking ranitidine. One patient had evidence of peripheral vascular disease. One patient had had a renal transplantation which had failed due to chronic vascular rejection.

Group 3 Ten patients (five men, five women) who were receiving continuous ambulatory peritoneal dialysis (median age 57 years, range 41-62 years). The median duration of dialysis was one year (range six months to three years). Three patients had evidence of peripheral vascular disease, two others were insulin dependent diabetics (one with retinopathy), two patients were hypertensive and both were taking nifedipine. All patients were
Correspondence to: Dr P Dandona Accepted for publication 23 October 1990 
taking ranitidine, alfacalcidol, and vitamin supplements. One patient had pruritus.

Group 4 Ten patients (six men, four women) who were receiving haemodialysis (median age 65 years, range 50-67 years). The median duration of dialysis was two years (range six months to 30 years). Three patients had peripheral vascular disease; pruritis was a problem in only one. None of these patients was taking antihypertensive drugs.

Controls Controls consisted of 27 normal subjects ( $18 \mathrm{men}$, nine women). None of these controls had any history of renal disease, occlusive vascular disease, or diabetes mellitus, and none of these volunteers had taken any medication for at least two weeks before the study. The controls were selected to include 17 with an age range between 19 and 45 years (median 27 years) while 10 had an age range between 59 and 80 years (median 69 years). There was no difference in plasma histamine concentrations between these two groups.

Blood samples were obtained in the fasting state. In patients receiving haemodialysis blood was obtained from the fistula/cannula before administration of heparin and dialysis was begun. This is important because heparin activates platelets ${ }^{13}$; the activation of platelets may result in altered uptake and possibly the release of histamine by platelets which may in turn affect plasma histamine concentrations.

\section{COLLECTION AND PREPARATION OF PLASMA}

Blood collection for the determination of plasma histamine concentrations needs extreme care because any accidental lysis of leucocytes will cause an increase in histamine in the plasma. Venous blood was drawn into plastic syringes with minimal stasis and immediately added to plastic tubes contining disodium EDTA (5 mmol/1 final concentration) as anticoagulant. Plasma was obtained by centrifugation at $1000 \times g$ for 15 minutes at $4^{\circ} \mathrm{C}$. The plasma was removed well clear of the buffy coat and stored at $-70^{\circ} \mathrm{C}$ until assay.

\section{ASSAY OF HISTAMINE IN PLASMA}

Plasma histamine concentrations were determined using a sensitive and specific monoclonal antibody radioimmunoassay for histamine. ${ }^{14}$ The assay entails the "acylation" of histamine into a succinyl-glycinamide derivative, and the histamine determination makes use of the competition of acylated histamine and ${ }^{125} \mathrm{I}$ acylated histamine for their binding to the mouse monoclonal antibody fixed on tubes. The lower limit of sensitivity in this RIA was $0.1 \mathrm{nmol} / 1$ for histamine and the standard curve permitted measurements between $0.1 \mathrm{nmol} / 1$ and 150

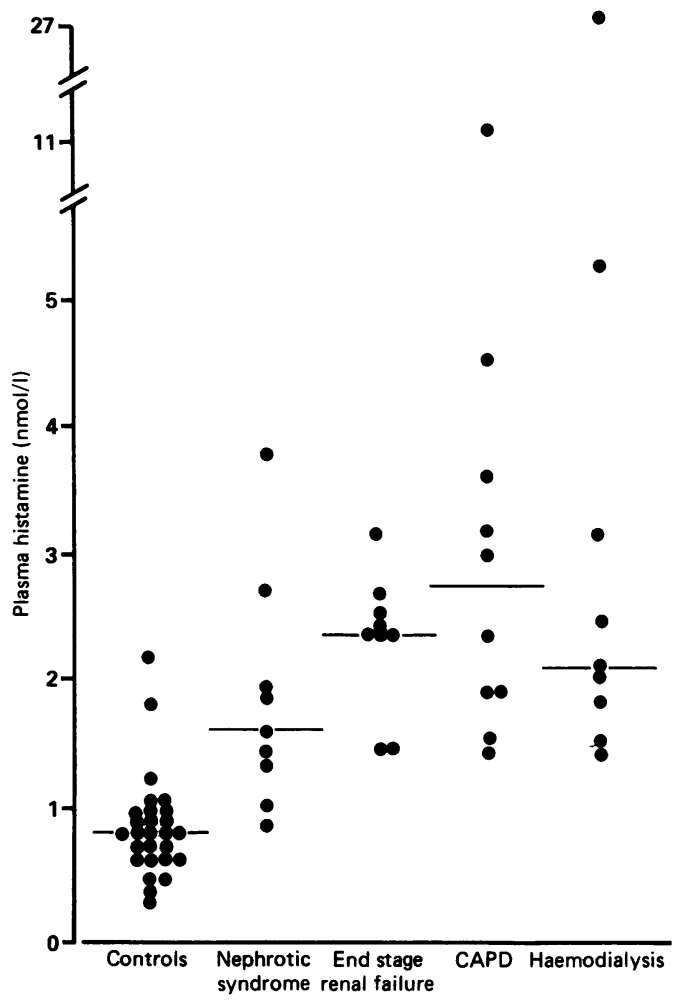

Plasma histamine concentrations. Control subjects; (NS) nephrotic syndrome; (ESRF) patients with end stage renal failure with no dialysis; (CAPD) continuous ambulatory peritoneal dialysis; (HD) haemodialysis. $C$ v. NS, C v. ESRF, C v. CAPD, C v. HD, $p<0.001$. All other permutations here not significant.

nmol/1. Intra-assay and interassay variations have been described previously. ${ }^{15}$

Statistical analysis was carried out using the Mann-Whitney (two-tailed) U test for unpaired data.

\section{Results}

Plasma histamine concentrations in the two groups of control subjects were unaffected by age. Thus plasma histamine concentrations in young subjects were median 0.78 , range 0.49 to $1.80 \mathrm{nmol} / \mathrm{l}$, and in elderly subjects were median $0 \cdot 67$, range $0 \cdot 31-2 \cdot 22 \mathrm{nmol} / \mathrm{l}$ ). There were no age related differences in plasma histamine concentrations in any of the patient groups. Therefore, for purposes of statistical analysis, the entire group of control subjects was regarded as one.

Plasma histamine concentrations are shown in the figure. The clinical and biochemical indices of the patient groups are shown in the table. Histamine concentrations in plasma were clearly raised in patients with chronic renal failure without dialysis, in those receiving peritoneal dialysis and haemodialysis, and in patients with nephrotic syndrome. Interest-

Median and range clinical indices of patients in groups 1-4

\begin{tabular}{|c|c|c|c|c|c|c|}
\hline Group & $\begin{array}{l}\text { Plasma creatine } \\
(\mu \mathrm{mol} / \mathrm{l})\end{array}$ & $\begin{array}{l}\text { Creatine clearance } \\
(\mathrm{ml} / \mathrm{min})\end{array}$ & $\begin{array}{l}\text { Plasma albumin } \\
(\mathrm{g} / \mathrm{l})\end{array}$ & $\begin{array}{l}\text { Urinary albumin } \\
(g / 24 h)\end{array}$ & $\begin{array}{l}\text { Plasma cholesterol } \\
(\mathrm{mmol} / \mathrm{l})\end{array}$ & $\begin{array}{l}\text { Serum triglyceride } \\
(\text { mmol } / \mathrm{l})\end{array}$ \\
\hline $\begin{array}{l}1 \\
2 \\
3 \\
4 \\
\text { Reference range }\end{array}$ & $\begin{array}{l}101(68-208) \\
690(500-1213) \\
784(375-1229) \\
804(349-906) \\
60-120\end{array}$ & $\begin{array}{l}115(27-139) \\
11 \cdot 1(5 \cdot 4-16 \cdot 0) \\
90-150\end{array}$ & $\begin{array}{l}38(32-47) \\
42(36-49) \\
44(38-50) \\
44(38-40) \\
40-50\end{array}$ & $\begin{array}{l}10.3(5.7-14.2) \\
0.6(<0.1-2.4) \\
<0.1\end{array}$ & $\begin{array}{l}7 \cdot 3(5 \cdot 2-15 \cdot 7) \\
6 \cdot 1(4 \cdot 9-6 \cdot 5) \\
6 \cdot 1(3 \cdot 5-10 \cdot 2) \\
6 \cdot 8(3 \cdot 3-8 \cdot 3) \\
3 \cdot 0-6 \cdot 5\end{array}$ & $\begin{array}{l}1.2(0.8-2 \cdot 1) \\
1.9(1.4-4.7) \\
2.5(0.8-3.5) \\
2.6(1.5-2.9) \\
0.2-1.5\end{array}$ \\
\hline
\end{tabular}


ingly, some of the highest plasma histamine concentrations were in patients with concomitant peripheral vascular disease. The two highest histamine values were both in patients with severe peripheral vascular disease, and both of whom had pruritus. The median histamine concentrations in patients with peripheral vascular disease, however, were not significantly greater than those in patients without peripheral vascular disease.

There were no significant correlations between histamine and creatinine clearance, plasma creatinine, plasma albumin and urinary albumin in any of the patient groups. Furthermore, there were no significant correlations between histamine, renal function, and lipid profiles in the patient groups.

\section{Discussion}

Our data clearly show a substantial increase in histamine concentrations in plasma obtained from patients with both nephrotic syndrome and chronic renal failure. This increase is similar to that previously reported, ${ }^{12}$ but two of our patients had very high plasma histamine concentrations and interestingly both had severe pruritus. The increase in plasma histamine concentrations may be due to renal insufficiency in patients with chronic renal failure because histamine, a relatively small hydrophilic molecule, is normally excreted in the urine. ${ }^{16}$ It is also known that parathyroid hormone, which is grossly increased in chronic renal failure, causes histamine to be released from mast cells which in turn are found in larger numbers in the skin of patients with chronic renal failure. ${ }^{17}$ These factors would have a cumulative effect resulting in the accumulation of histamine in plasma, but they do not exclude the possibility that other factors may be involved in the increase in plasma histamine concentrations. The possible mechanisms underlying the increase in plasma histamine in nephrotic syndrome require further investigation.

The clinical implications of these observations, though not obvious, are potentially interesting. It has been suggested that histamine may be involved in the pathogenesis of occlusive vascular disease, a common complication of chronic renal failure and nephrotic syndrome. Furthermore, plasma histamine concentrations and leucocyte and platelet histamine contents have been shown to be increased in patients with peripheral vascular disease and diabetes mellitus, a known risk factor for atherosclerosis. ${ }^{15,18}$ Histamine is likely to cause a change in the permeability of the endothelium of capillaries and of the tunica intima of larger blood vessels. ${ }^{19,20}$ Histamine has many effects on vascular endothelium; these include a widening of interendothelial gaps by endothelial contraction, ${ }^{21}$ an increase in endothelial pinocytosis of plasma macromolecules, ${ }^{22}$ dissociation of endothelial actin cables, ${ }^{23}$ an increase in endothelial prostacyclin production $^{24}$ and an increase in polymorphonuclear leucocyte migration into the endothelium. ${ }^{25}$ These events lead to an increased influx of atherogenic plasma macromolecules, platelets, and monocytes into the blood vessel wall, and may start the initial chain of events leading to the preatherosclerotic lesion. It is also possible that an increase in plasma histamine concentrations may participate in the induction and perpetuation of glomerular capillary injury through enhanced capillary permeability and the leakage or deposition of macromolecules like immunoglobulins and complement.

1 Selye H. The mast cells. Washington, DC. Butterworths, 1965.

2 Hartman WJ, Clarke WG, Cyr SD. Histidine decarboxylase activity from chronic myelogenous leukemia patients. Origin of blood histamine Proc Soc Exp Biol Med 1961;107:123-5.

3 Kahlson G, Rosengren E, Shavn D, Thunberg R. Mobilisation and formation of histamine in the gastric mucosa as related to acid secretion. J Physiol Lond 1964;174:400-16.

4 Abboud HE, Murray J, Thorgeirsson G. Histadine decarboxylase mediated histamine synthesis in cultured human endothelial cells. Clin Res 1982;30:166A.

5 Hollis TM, Gallick SG, Orlidge A, Yost YC. Aortic endothelial and smooth muscle histamine metabolism. Relationship to aortic 125-I albumin accumulation in experimental diabetes Arteriosclerosis 1983:3.599-606.

6 Gill DS, Thompson CS, Dandona P. Increased histamine in plasma and tissues of diabetic rats. Diabetes Res 1988;7: plasm.

7 Bolton WR, Spargo BA, Lewis E. Chronic autologous immune complex glomerulopathy. J Lab Clin Med 1974;83:695-703.

8 Ford PM. Passive serum sickness in the mouse: the role of vasoactive amines in glomerular deposition of immune complexes. BrJ Exp Pathol 1976;57:148-51.

9 Markle RA, Hollis TM, Cosgarea AJ. Renal histamine increase in streptozotocin-diabetic rat. Exp Mol Pathol 1986;44:21-8.

10 Beall GN, Vavarsdal PP. Histamine metabolism in human disease. J Clin Invest 1959;28:676-83.

11 Wilhelms OH, Kreusser W, Eberhard R. Parathyroid hormone elicits histamine release from mast cells. Mineral Electrolyte Metab 1981;6:294-300.

12 Stockenhuber F, Sunder-Plassmann GS, Balcke P. Increased plasma histamine levels in chronic renal failure. N Engl J Med 1987;317:386.

13 Mikhailidis DP, Barradas MA. Low molecular weight heparin(oid)s. Are they the answer to heparin associated thrombocytopenia (and thrombosis)? J Drug Dev 1989;1:265-73.

14 McBride P, Bradley D, Kaliner M. Evaluation of a radioimmunoassay for histamine measurement in biological fluids. J Allergy Clin Immunol 1988;82:638-46.

15 Gill DS, Barradas MA, Fonseca VA, Dandona P. Plasma histamine concentrations are elevated patients with diabetes mellitus and peripheral vascular disease. Metabolism 1989;38:243-7.

16 Wetterquist $\mathrm{H}$. Histamine metabolism and excretion. In: RE Silva, ed. Handbook of experimental pharmacology. Vol 18: Part 2. Berlin: Springer-Verlag, 1978:131-50.

17 Matsumoto $M$, Ichimaru K, Horie A. Pruritis and mast cell proliferation of the skin in end stage renal failure. Clin Nephrol 1985;23:285-8.

18 Gill DS, Barradas MA, Fonseca VA, Gracey L, Dandona P. Increased histamine content in leucocytes and platelets of patients with peripheral vascular disease. Am J Clin Pathol 1988;89:622-6.

19 Majno G, Gilmore V, Levanthal M. On the mechanism of vascular leakage caused by histamine-type mediators. A microscopic study in vitro. Circ Res 1967;21:833-47.

20 Killacky JJF, Johnston MG, Movat MG. Increased permeability of microcarrier-cultured endothelial monolayers in response to histamine and thrombin. Am J Pathol 1986;122:50-61.

21 Majno G, Shea SM, Levanthal M. Endothelial contraction induced by histamine-type mediators. An electron induced by histamine-type mediators. An

22 Orlidge A. Bovine aortic endothelial cells-Histamine metabolism and its relationship to fluid phase endocytosis: metabolism and its relationship to fluid phase endocytosis: Regulation by insulin, histamine receptors and alphahydrazinohistadine. PhD Thesis. The Penn

23 Welles SL, Shepro D, Hechtman HB. Vasoactive amines modulate actin cable (stress fibres) and surface area in cultured bovine endothelium. J Cell Physiol 1985;123:337-42.

24 Baenziger NL, Fogerty FJ, Mertz LF, Chernuta LF. Regulation of histamine-mediated prostacyclin synthesis in human vascular endothelial cells. Cell 1981;24:915-23.

25 Doukas J, Shewpro D, Hechtman HB. Vasoactive amines directly modify endothelial cells to affect polymorphonuclear leucocyte diapedesis in vitro. Blood 1987;69: 1563-9. 